\title{
Atualidades/Actualities
}

\section{A OFERTA E A PROCURA DE SAÚDE IMEDIATA ATRAVÉS DO MEDICAMENTO: PROPOSTA DE UM CAMPO DE PESQUISA}

Fernando Lefèvre *

LEFEVRE, F. A oferta e a procura de saúde através do medicamento: proposta de um campo de pesquisa. Rev.Saúde públ., S. Paulo, $21: 64-7,1987$.

RESUMO: Procura-se discutir - de um ponto de vista teórico - o uso simbólico do medicamento como implicando uma "economia" de um "processo longo" e dos aspectos complexos da saúde tanto a nível social como individual. A saúde é, sempre, um "processo longo" na medida em que não pode ser separada de um projeto de vida, projeto esse que se situa numa escala de tempo outra que aquela presente na fruição de produtos de consumo, como o medicamento. A "saúde imediata" é proposta como resultante desejada ou significado deste processo simbólico. É ressaltada a dimensão político-ideológica do problema, estreitamente vinculada à idéia do medicamento como mercadoria. Discute-se a oposição: consumo com prescrição médica versus consumo sem prescrição médica como sendo uma falsa oposição, a ser substituída pela oposição: consumo simbólico versus consumo não simbólico de medicamentos. Propõe-se finalmente, um novo campo de pesquisa em saúde pública: a oferta e procura de bens simbólicos que satisfaçam o desejo de "saúde imediata".

UNITERMOS: Medicamentos. Saúde. Semiótica. Automedicação.

\section{INTRODUÇÃO}

O presente ensaio busca retomar e aprofundar as idéias discutidas em trabalho anterior ${ }^{4}$ sob a mesma temática.

Alguns importantes acréscimos e modificações, em relação ao trabalho anterior, devem ser assinalados.

- a função simbólica do medicamento como implicando uma "economia" daquilo que é longo e multidimensional na saúde;

- esta "economia" como sendo um processo ideológico;

- a noção de "saúde imediata" como resultante desejada desta economia;

- as sub-classes de saúde imediata;

- o medicamento como mercadoria-símbolo;

- a crítica da oposição: consumo com prescrição versus consumo sem prescrição e a sua substituição pela oposição: consumo simbólico versus consumo não simbólico de medicamentos;

- a introdução de outras mercadorias-símbolo na área de saúde.

\section{MEDICAMENTO COMO SIGNO}

Como produto simbólico, o medicamento pode ser visto como um signo ou símbolo ${ }^{2}, 5$ composto de uma realidade material (significante) que, no caso é a pilula, a solução, a ampola, etc., que remete a um conceito (significado) que é a Saúde.

A semiótica e a lingüística modernas ampliaram o conceito de "significado", tradicionalmente visto como imagem mental ${ }^{2}$ ou estado de consciência ${ }^{1}$, incluindo nele, e na semântica, conteúdos como as ordens, os atos de linguagem ${ }^{8}$, a expressão dos sentidos, como no caso das interjeições e, de uma maneira geral, a pragmática ${ }^{2}$, ou seja, os resultados práticos obtidos com o consumo do significado.

Sendo assim, é perfeitamente possível ver-se o medicamento como um signo cujo significado vai bem mais além da simples idéia, conceito imagem merital de "saúde", implicando também, e sobretudo, a própria realização ou obtenção da saúde.

A possibilidade de obtenção da saúde através do medicamento permite o seu uso, a sua utilização prática, como signo ou símbolo, entendidos estes na acepção ampla (e rica de virtualidades teórico- práticas) conferida ao termo por Pierce ${ }^{5}$.

Com efeito, como Pierce ${ }^{5}$ define signo ou símbolo? $\mathrm{Na}$ tradução e interpretação de $\mathrm{Eco}^{2}$ como "alguma coisa que, aos olhos de alguém, está por outra coisa, a algum respeito ou por alguma sua capacidade" (p. 26). Agrega Eco ${ }^{2}$ comentando a definição de Pierces: "A algum respeito significa que o signo não representa a totalidade do objeto, mas por via de abstraçōes diversas - $O$ representa de um certo modo ou como o fim de um certo uso prático" (p. 26).

Exploremos esta definição e os comentários correlatos.

- Departamento de Prática de Saúde Pública da Faculdade de Saúde Pública da Universidade de São Paulo - Av. Dr. Arnaldo, 715 - 01255 - São Paulo, SP - Brasil. 
A primeira "alguma coisa" é um signo, composto de uma realidade material, um estímulo, que é portador de uma idéia, de uma possibilidade real, de uma ação, de um uso prático.

Esta "alguma coisa" está por uma segunda coisa, está no lugar desta segunda coisa, representa, substitui esta segunda "coisa".

A palavra ou signo "maçẫ" está no lugar das, ou representa as maçãs concretas existentes no mundo; assim como o depu tado está no lugar de uma parcela do povo, que ele representa; assim como o símbolo da foice e do martelo está no lugar da luta das classes operária e camponesa; assim como o medicamen to está no lugar da saúde.

Por estes exemplos, percebe-se que "estar no lugar" pode implicar várias idéias. Ê nesse sentido que $\mathrm{Eco}^{2}$ afirma que o signo representa o objeto "de um certo ponto de vista" ou "com o fim de um certo uso prático".

\section{MEDICAMENTO E SAUDE}

Caberia então indagar de que ponto de vista ou, a partir de que uso prático, o medicamento está no lugar da saúde?

Poderíamos levantar várias possibilidades. Antes disso, porém, é preciso, mais uma vez, explicitar a idéia de que a saúde, como toda a reflexão contem. porânea em saúde pública confirma, é, inegavelmente, um processo social, cultural, psicológico e biológico longo e complexo, em outras palavras, multidimensional.

Isto posto, quando se afirma que o medicamento está no lugar da saúde esta afirmação tem um conteúdo muito preciso.

"Estar no lugar", aqui, significa estar indevidamente no lugar. É o mesmo processo da mentira, que está no lugar da verdade; da fala ou da ação com segundas intençðes, não reveladas, que está no lugar destas segundas intenções; da pista falsa deixada pelo bandido, que está no lugar da pista verdadeira.

No caso do medicamento, "estar no lugar" significa escamotear, fazer abstração, apagar, colocar entre parênteses, impedir que se veja, a saúde enquanto totalidade ou "processo longo".

Resumidamente, poderíamos dizer, no que tange ao medicamento, que o processo de abstração a que se refere $\mathrm{Eco}^{2}$ é um processo não apenas semiótico mas também ideológico, no sentido clássico de falsa consciência ${ }^{6}$, na medida em que este conceito im. plica em escamotear, velar, impedir que se veja a realidade na sua dinâmica contraditória e conflitiva.

No momento em que se constitui como símbolo, o medicamento faz a "economia", poupa o trabalho duro, político e pessoal, necessário para que se obte- nha a saúde. Realiza um "curto circuito", procurando apagar a doença como indicador ou sintoma de problemas, contradições, dificuldades, injustiças, tanto a nível pessoal como social.

Esta operação poupadora de esforço, de dor, de denúncia de injustiça implica, do ponto de vista do indivíduo, a fantasia de redução mágica do complexo, do complicado, do frustrante, do arriscado, do trabalhoso, ao uno, ao simples, ao fácil, ao acessível, ao visível, ao concreto, ao "aqui e agora", ao imediato.

\section{SIMBOLO, CIÊNCIA E MERCADORIA}

Desde sempre esta fantasia simbólica esteve presente no uso pessoal do medicamento, e das drogas em geral.

O que muda, e muito, é que nas chamadas sociedades de consumo esta fantasia pessoal e, a nível social, a ideologia que the dá sustentação, sâo mercadorias a serem vendidas e compradas no mercado, o que faz com que o seu consumo necessite ser permanentemente renovado ou reproduzido.

Como conseguir que a sociedade moderna consuma permanentemente a fantasia e a ideologia da "saúde imediata"?

Associando-a a algo solido e respeitável como a Ciência, que fornece o álibi para o exercício desta fantasia na medida em que a nível do racional, do consciente, o indivíduo e a sociedade estão consumindo produtos da tecnologia científica.

\section{MEDICAMENTO E LUTA DE CLASSES}

Mas a Ciência, por seu lado, é força produtiva, atuante no quadro das relações de produção, exercendo, também, conforme a posição de classe do agente social cientista da saúde e conforme a conjuntura histórica, funções técnico políticas visando o favorecimento da emergência da consciência de classe $^{6}$.

Nesse sentido, como fazendo parte da luta de classes, no campo da saúde temos, esquematicamente, duas posições com respeito ao medicamento, ambas apoiadas na Ciência:

- a inserção do medicamento como um componente da problemática biopsicossocial geradora de estados de saúde e doença, a nível individual e coletivo;

- o uso simbólico do medicamento, que permite a obtenção ou reobtenção rápida ou imediata da saúde.

O uso não simbólico da droga implica em não reduzir a doença e a saúde a fenômenos orgânicos ${ }^{4}$, 
LEFEVRE, F, A oferta e a procura de saúde através de medicamento: proposta de um campo de pesquisa. Rev. Sanide públ., S. Paulo, $21: 64-7,1987$.

em considerá-las, sempre, como fenômenos inextricavelmente biopsicossociais. Neste quadro, o medicamento é um dos componentes (não obrigatório, por suposto) de um processo longo e multidimensional implícito no enfrentar (no caso da doença) ou no evitar (no caso da saúde) situações de desequilíbrio que levem à doença. Isto implica, é claro, em descaracterizar o medicamento (e não apenas o "over the counter") como um bem terminal de consumo, para vê-lo como um bem intermediário para uso técnico, da mesma natureza da vidraria para exame de laboratório, por exemplo.

Implica, tamberm, em descaracterizá-lo como coroamento necessário da consulta medica ${ }^{3}$.

\section{UMA FALSA OPOSIÇÃO}

Simbolicamente, o medicamento pode ser usado tanto no contexto da assistência de saúde quanto fora dela.

Vale assinalar, portanto, que a questão: "tomar versus não tomar remédio com receita médica" é uma falsa questão. Com efeito, tal como o definimos, pode estar havendo uso simbólico do medicamento mesmo quando este é receitado por médico.

A verdadeira questão é o uso simbólico versus o uso não simbólico do medicamento. É claro, por outro lado, que fora de um contexto de assistência médica é muito pouco provável que não esteja havendo consumo simbólico de medicamento.

No contex to da assistência de saúde onde, erradamente, se acredita que esteja sempre havendo uso terapêutico do medicamento, o uso simbólico se faz dentre outros modos por pressão direta do clierıte $^{3}$, ou com o intuito de fazer a consulta mé. dica "render", ou para contornar a relação médico paciente, tudo isso associado ao tipo de formação do médico, que o acaba levando a supervalorizar o medicamento no processo de obtenção ou restabe. lecimento da saúde ${ }^{7}$.

\section{SUB-CLASSES DE MERCADORIAS-SIMBOLO}

A "saúde imediata" que é buscada através do medicamento reveste-se, segundo cremos, de várias formas ou modalidades.

"Saúde imediata" é um conceito genérico. E claro que cada indivíduo, com sua história de vida particular, realiza significados próprios para os seus desejos de saúde.

No entanto, pode-se propor algumas sub-categorias in termediárias, menos genéricas mas não indivi. duais, que permitem ir um pouco mais a fundo na caracterização do desejo de "saúde imediata".
Nesse sentido, é provável que os indivíduos, sob a rubrica genérica da "saúde imediata", desejem viver estados mais concretos de saúde que configuram algumas sub-classes de "saúde imediata", tais como:

- alívio (de dor ou de desconforto), proporcionado por analgésicos e afins;

- potência ou vida proporcionado por vitaminas, estimulantes e algumas drogas como co. caína;

- proteção (ou, em termos da chamada cultura popular, desejo de "fechamento de corpo") proporcionado por vacinas e antibioticos (quando usados popularmente, como "remedios fortes");

- morte (no sentido figurado do termo) proporcionado por calmantes e por algumas drogas (as que levam aos chamados "paraísos artificiais").

Sob o ângulo social, lançando mão das sub-classes de "saúde imediata", fica mais fácil visualizar a problemática da oferta de medicamentos como mercadorias-símbolo.

Com e feito, quando o medicamento está sendo oferecido no mercado como mercadoria-símbolo, - que está sendo oferecido não é propriamente a "saúde imediata" mas estados bem mais concretos, encaixáveis sob esta rubrica genérica.

Abstrações - como saúde - não são coisas vendáveis, mas "alívio para dores de cabeça", "potência sexual", "disposição para os estudos e para o trabalho", "apetite", "paz de espírito", sim, o são.

\section{CONCLUSÃO: UM DUPLO CAMPO DE PESQUISA}

Como conclusão, poderíamos sugerir um duplo campo de pesquisa: a oferta e a procura de mercadorias simbólicas que satisfaçam, em termos sociais, ’a necessidade, forjada pelas classes dominantes, ou em termos psicológicos, à fantasia, da saúde imediata.

A nivel da oferta, este campo de investigação seria teoricamente amparado por uma sócio se. miótica da saúde imediata que trabalharia, com o instrumental da sociologia, da antropologia, da semiótica e das disciplinas da saúde pública, as questões relativas a produção social da necessidade de "saúde imediata" e das mercadorias-símbolo encarregadas de satisfazer esta necessidade.

Neste contexto fica claro que o medicamento é apenas uma das mercadorias-símbolo possíveis de serem oferecidas ao consumo.

Outras mercadorias-símbolo seriam, por exemplo, as cirurgias, que com todo o seu formidável aparato visual, produzem um incontestável efeito simbólico no ciđadão comum, permitindo que operações como a cesareana possam ser vistas e consu- 
LEFEVRE, F. A oferta e a procura de saúde através de medicamento: proposta de um campo de pesquisa. Rev. Saúde públ., S. Paulo, $21: 64-7,1987$.

midas como mercadorias que fazem, para o médico, a economia do longo processo natural de nascimento e, para o paciente, a economia das "dores do parto".

A nivel da procura, este campo de investigação deve - lançando mão da psicologia, da psicanálise, da semiótica - estudar a produção individual do sentido, ou mais precisamente, as racionalizações que os individuos desenvolvem e que permitem a internalização das necessicaúes *, socialmente gera. das, de "saúde imediata".

Pretende o autor em projeto de tese a ser desen. volvido, analisar, no campo da procura da "saúde imediata", o problema específico de como o doente crônico racionaliza, lançando mão de símbolos como o medicamento e outros, aquilo que, no caso, seria a reobtenção imediata da saúde perdida.

LEFEVRE, F. [ Supply and demand of "instant health" by means of medicines: a proposal for research]. Rev.Saúde púb1., S. Paulo, $21: 64-7,1987$.

ABSTRACT: The symbolic utilization of medicines as implying an abridgement of a long and multidimensional process which is necessary for achieving health status, socially and individually speaking, is discussed from a theoretical point of view. "Instant health" is proposed as the desired result or as the meaning of this symbolic process. The politico-ideological dimensions of the problem as strictly relation to the idea of medicines as merchandise is discussed. The paper also considers the false opposition: prescribed versus nonprescribed medicines and offers a new one - symbolic versus nonsymbolic use of medicines. Finally, a new field of research is proposed in public health - the supply and demand of symbolic goods which would satisfy the desire for "instant health".

UNITERMS: Drugs. Health. Semiotics. Self medication.

\section{REFERÊNCIAS BIBLIOGRÁFICAS}

1. BUYSSENS, E. Semiologia e comunicą̧āo lingü istica. São Paulo, Cultrix/EDUSP, 1972.

2. ECO, U. O signo. Lisboa, Editorial Pioneira, 1981.

3. KNAPP, D.A \& KNAPP, D.E. Decision-making and self medication: preliminary findings. Amer.J.hosp. Pharm., 29:1005-12, 1972.

4. LEFÈVRE, F. A função simbólica dos medicamentos. Rev. Saúde públ., S. Paulo, 17: 500-3, 1983.

5. PIERCE, C.S. Semiótica e filosofia. São Paulo, Cultrix/EDUSP, 1975.
6. POULANTZAS, N. Les classes sociales dans le capitalisme d'aujourd'lui. Paris, Seuil, 1974.

7. SASSAKI, F.H Prescrição: uma análise institucional. São Paulo, 1984. [Tese de Doutoramento - Faculdace de Saúde Pública da USP].

8. SEARLE, J. R. Les actes de language. Paris, Hermann, 1972.

Recebido para publicação em 29/07/1986

Aprovado para publicação em 12/11/1986

* Recordemos que segundo a teoria da ideologia, o indivíduo crê que são deles as necessidades forjadas pelas classes dominantes. 